\title{
A RESEARCH ON KNOWLEDGE REDUCTION OF INFORMATION SYSTEMS BASED ON SUB- CONSCIOUSNESS
}

\author{
Wei Huang, Cong Liu, Xiao-ping Ye \\ School of Information Science and Technology, Sun Yat-sen University
}

\begin{abstract}
The information system based on sub-consciousness is a new type of information system developed from the incomplete information system by introducing the new concept of sub-consciousness based on the possible relations among the domains of the attributes in the information system. In this paper, we will discuss the knowledge reduction in the information system based on sub-consciousness, we also propose the concept of rationally guided emotional reduction in the information system based on sub-consciousness which is then compared with the rational reduction and the emotional reduction in the information system based on sub-consciousness.
\end{abstract}

Key words: Information system, Sub-consciousness, Knowledge reduction, Reduction of sub-consciousness

\section{INTRODUCTION}

The classical Rough Set Theory has been very successful in knowledge acquisition in the complete information system [1]. In consideration of that some of the attributes in the information system might have absent value, the complete information system was developed into the incomplete information system. [2]-[5] are several extensions to the classical rough set theory considering some different connotations of the absent value respectively. In the theoretical framework of the information system based on subconsciousness proposed in [6], the complete information system with the classical rough set method and those with extended rough set method can be regarded as some special cases. The knowledge reduction is more 
complicated in the information system based on sub-consciousness than those of the complete and incomplete information systems with the introduction of the mechanism of sub-consciousness, so in this paper, we will propose the concept of rationally guided emotional reduction in the information system based on sub-consciousness.

\section{A NEW KIND OF EMOTIONAL REDUCTION}

In this section, the definition of a new kind of emotional reduction in the information system based on sub-consciousness is given that is different from that defined in reference [6]. All the symbolic and denotational convention in this paper is conform to that in reference [6]. Because of space limitation, readers are recommended to reference [6] for related concepts and denotations.

Definition 2.1 Let $\mathrm{c}(\mathrm{c} 1, \mathrm{c} 2, \ldots, \mathrm{cn})$ and $\mathrm{d}(\mathrm{d} 1, \ldots, \mathrm{dm})$ to be vectors, $A$ and $\mathrm{B}$ are sets of attributes (where $|A|=n,|B|=m$ ). We define a function Replace $(c, d$, $A, B)=e=(e 1, \ldots, e n)$, where $e i=d j$, if $a i \in A, b j \in B$ and $a i=b j$; ei $=c i$ otherwise.

Definition 2.2 Let $B \subseteq A T(B=\{b 1, b 2, \ldots, b m\})$, then for any $x, y \in U$, we have $B(x)=(b l(x), \ldots, b m(x))$. For any attribute $a i \in A T$, if there is an attribute $b j \in B$ such that ai $=b j$, we mark the arbitration function $h_{i}$ on ai as $h_{b j}$, and use $h(B, x, y)$ to represent the vector $\left(h_{b l}(x, y), \ldots, h_{b m}(x, y)\right)$.

Definition 2.3 An attribute set $\mathrm{B}$ is called emotionally reducible if and only if $\quad(\forall \mathrm{x}, \mathrm{y} \in \mathrm{U})\left(\exists \mathrm{d} \in \prod_{0<i<\mathrm{n}+1} \quad\right.$ and $\left.\quad \mathrm{ai}_{\mathrm{B}} \mathrm{D}_{\mathrm{i}}\right)$ $((\mathrm{F}(\mathrm{x}, \mathrm{y})=\mathrm{H}(\mathrm{c})) \rightarrow(\mathrm{H}(\mathrm{c})=\mathrm{H}($ Replace $(\mathrm{c}, \mathrm{d}, \mathrm{AT}, \mathrm{B}))))$ holds. If there is no another attribute set $\mathrm{C}(\mathrm{B} \subset \mathrm{C} \subseteq \mathrm{AT})$ that is emotionally reducible, the $\mathrm{A}=\mathrm{AT}-\mathrm{B}$ is called the knowledge reduction for the experiential data $\mathrm{S}$ or emotional reduction and d is called the origin.

From definition 2.3, we know that the knowledge reduction in the traditional complete and incomplete information system is the emotional reduction, where origin $d$ takes the form (true,..., true) (the number of true is $|\mathrm{AT}-\mathrm{A}|$ totally). If we replace part $<1>$ of the configuration of subconsciousness $\Psi$ with $\mathrm{D}_{\mathrm{i}}=$ Bool, part $<3>$ with $\mathrm{H}(\mathrm{c} 1, \mathrm{c} 2, \ldots, \mathrm{cn})=\mathrm{c} 1 \vee \mathrm{c} 2 \vee \ldots \vee \mathrm{cn}$, then for the information system $\mathrm{S}$ with sub-consciousness $\Psi$, the origin takes the form (false,..., false) (the number of false is $|\mathrm{AT}-\mathrm{A}|)$. 


\section{THE RATIONALLY GUIDED EMOTIONAL REDUCTION IN THE INFORMATION SYSTEM BASED ON SUB-CONSCIOUSNESS}

For we have introduced the sub-consciousness $\Psi$ and its attribute correlation function $\mathrm{H}$ into the information system based on subconsciousness, we could use their definition to guide the knowledge reduction. The attribute correlation function could be defined as a conjunction form (or a disjunction form), that is the definition of $\mathrm{H}$ could appear as $\mathrm{H}(\mathrm{c} 1, \mathrm{c} 2, \ldots, \mathrm{cn})=\mathrm{fl}(\mathrm{Cl}) \wedge \ldots \ldots \wedge \mathrm{fs}(\mathrm{Cs})($ or $\mathrm{fl}(\mathrm{Cl}) \vee \ldots \ldots \vee \mathrm{fs}(\mathrm{Cs}))$, where $\mathrm{Ck}(0<\mathrm{k}<\mathrm{s}+1)$ are subsets of $\{\mathrm{c} 1, \mathrm{c} 2, \ldots, \mathrm{cn}\}, \mathrm{fk}(0<\mathrm{k}<\mathrm{s}+1)$ are some middle functions whose range is Bool. If we regard the definition of $\mathrm{H}$ as a predicate form, each $\mathrm{fs}(\mathrm{Cs})$ could be regarded as its sub conjunction form (or sub disjunction form). In fact, each $\mathrm{Ck}$ corresponds to one of the subsets $\mathrm{Ak}$ of the attribute set AT, and all $\mathrm{Ck}$ make up an coverage of the attribute set AT. If we restrict the reduction to the subset of $\{A 1, \ldots, A s\}$, when $s<<$, the complexity of the reduction will be reduced largely.

Definition 3.1 Let AT $(\mathrm{AT}=\{\mathrm{a} 1, \mathrm{a} 2, \ldots, \mathrm{an}\})$ be the rational reduction of information system $S$, and sub-consciousness $\Psi$ to be the reduced subconsciousness of the information system $\mathrm{S}$, and its attribute correlation function could be written as $\mathrm{H}(\mathrm{c} 1, \mathrm{c} 2, \ldots, \mathrm{cn})=\mathrm{fl}(\mathrm{Cl}) \wedge \ldots \ldots \wedge \mathrm{fs}(\mathrm{Cs})$ (or $\mathrm{fl}(\mathrm{Cl}) \vee \ldots \ldots \vee \mathrm{fs}(\mathrm{Cs}))$. We construct a new information system $\mathrm{S}^{\prime \prime}\left(\mathrm{U}^{\prime \prime}, \mathrm{BT}\right)$ based on $\mathrm{S}$, where $\mathrm{BT}(\mathrm{BT}=\{\mathrm{b} 1, \mathrm{~b} 2, \ldots, \mathrm{bs}\})$ is the attribute set of $\mathrm{S}^{\prime \prime}$. For each object $\mathrm{x}$ in $\mathrm{S}$, there is a object $\mathrm{x}^{\prime \prime}$ in $\mathrm{S}^{\prime \prime}$ which corresponds to $\mathrm{x}$, where $\operatorname{bi}\left(x^{\prime \prime}\right)=\operatorname{Ai}(x)(0<i<s+1)$. We establish a sub-consciousness $\Psi^{\prime \prime}$ in the information system $\mathrm{S}^{\prime \prime}$ as follows:

$<1>\mathrm{D}^{\prime \prime}{ }_{\mathrm{i}}=$ Bool, where $0<\mathrm{i}<\mathrm{s}+1$.

$<2>\mathrm{h}^{\prime \prime}{ }_{\mathrm{i}}\left(\mathrm{bi}\left(\mathrm{x}^{\prime \prime}\right), \mathrm{bi}\left(\mathrm{y}^{\prime \prime}\right)\right)=\mathrm{fi}(\mathrm{h}(\mathrm{Ai}, \mathrm{x}, \mathrm{y}))$, where $0<\mathrm{i}<\mathrm{s}+1$.

$<3>\mathrm{H}^{\prime \prime}(\mathrm{c} 1, \mathrm{c} 2, \ldots, \mathrm{cs})=\mathrm{c} 1 \wedge \mathrm{c} 2 \wedge \ldots \wedge \mathrm{cs} \quad$ (or $\left.\mathrm{c} 1 \vee \mathrm{c} 2 \vee \ldots \vee \mathrm{cs}\right)$, where $\mathrm{c} 1, \mathrm{c} 2, \ldots, \mathrm{cs} \in$ Bool.

Let it is the emotional reduction $\mathrm{D}=\{\mathrm{d} 1, \mathrm{~d} 2, \ldots, \mathrm{dr}\}=\left\{\mathrm{b}_{\mathrm{d} 1}, \mathrm{~b}_{\mathrm{d} 2}, \ldots, \mathrm{b}_{\mathrm{dr}}\right\}$ of the information syste $S^{\prime \prime}$ (its origin takes the form (true,...,true) or (false,...,false)), then we call the attribute set A the rationally guided emotional reduction (or the emotional reduction guided by subconsciousness $\Psi)$ if and only if $(\forall \mathrm{a} \in \mathrm{A})(\exists \mathrm{i})\left((0<\mathrm{i}<\mathrm{r}+1) \wedge\left(\mathrm{a} \in \mathrm{A}_{\mathrm{di}}\right)\right)$. Similar to the definition of the rationally (or emotionally) reduced sub-consciousness, the rationally guided emotional reduced sub-consciousness $\Psi$ ' is created by removing the range $D_{i}$ and the arbitration function $h_{i}$ that correspond to the attribute that is in AT-A, and by removing from the definition of the attribute correlation function $\mathrm{H}$ the sub conjunction forms or the sub disjunction 
forms (i.e. fi(Ci)) that correspond to the emotionally reduced attributes in the information system $\mathrm{S}^{\prime \prime}$.

From definition 3.1 we know that for any $\mathrm{x}, \mathrm{y} \in \mathrm{U}$ there are corresponding $x^{\prime \prime}, y^{\prime \prime} \in U^{\prime \prime}$ such that $F(x, y)=F^{\prime \prime}\left(x^{\prime \prime}, y^{\prime \prime}\right)$. So, we could get the following theorem directly.

Theorem 3.1 Let A be the rationally guided emotional reduction of the information system $\mathrm{S}(\mathrm{U}, \mathrm{AT})$ with sub-consciousness $\Psi$, and the subconsciousness $\Psi$ ' to be corresponding reduced sub-consciousness, then any $\mathrm{x} \in \mathrm{U}: \operatorname{SIM}_{\Psi}(\mathrm{x})=\operatorname{SIM}_{\Psi}(\mathrm{x})$ and $\operatorname{SIM}_{\Psi}{ }^{-1}(\mathrm{x})=\operatorname{SIM}_{\Psi},{ }^{-1}(\mathrm{x})$.

Whether the definition of $\mathrm{H}$ is $\mathrm{H}(\mathrm{cl}, \mathrm{c} 2, \ldots, \mathrm{cn})=\mathrm{fl}(\mathrm{Cl}) \wedge \ldots \ldots \wedge \mathrm{fs}(\mathrm{Cs})$ or $\mathrm{fl}(\mathrm{C} 1) \vee \ldots \ldots \vee \mathrm{fs}(\mathrm{Cs})$, each $\mathrm{fi}(\mathrm{Ci})(0<\mathrm{i}<\mathrm{s}+1)$ could be regarded as a predicate form. We can regard $(\mathrm{U}, \mathrm{Ai})$ as a new information system $\mathrm{Si}$, and that part $<1>$ and part $<2>$ of the sub-consciousness configuration are the corresponding domain of the attribute set $\mathrm{Ai}$ and the arbitration function in the original information system, the $\langle 3\rangle$ part, i.e. the definition of the attribute correlation function $\mathrm{H}$, is $\mathrm{fi}(\mathrm{Ci})$. Since all $\mathrm{fi}(\mathrm{Ci})(0<\mathrm{i}<\mathrm{s}+1)$ are predicate forms, they could also be conjunction form or disjunction form, and the rationally emotional reduction could also be performed on them. Therefore, the process to perform rationally guided emotional reduction in the whole information system is a hierarchical process, which could be topdown or bottom-up. Comparing definition 3.1 and definition 2.3, we could get the following theorem.

Theorem 3.2 If the attribute set B is emotionally reducible in the information system $S$ with sub-consciousness $\Psi$, it is not certain whether it is rationally guided emotionally reducible, vice versa.

Practically, when performing reduction on an information system, the rational reduction should be performed first, and then the rationally guided emotional reduction to reduce the attribute set, and finally performing the emotional reduction on the attribute set with the newly reduced subconsciousness.

Our next research is to find some efficient algorithms for the rational reduction, emotional reduction, the rationally guided emotional reduction and especially the hierarchical rationally guided emotional reduction.

\section{REFERENCES}

I. Z.Pawlak, J.GBusse, R.Slowinski et al. Rough sets. Communications of the ACM, 1995, $38(11): 89 \sim 95$.

2. Kryszkiewicz M. Properties of incomplete information systems in the framework of rough sets. In Pollkowski L.,Skowron A.(eds.) Rough Sets in Data Mining and Knowledge Discovery,Physics-Verlag, 1998,422-450.

3. Kryszkiewicz M. Rough set approach to incomplete information systems, Information Sciences 112(1998), 39-49. 
4. Stefanowski J, Tsoukias A. On the extension of rough sets under incomplete information, On $7^{\text {th }}$ international workshop, RSFDGrC'99 Yamaguchi, Japan, November 9-11, 1999 Proceedings. 73-81.

5. Wang Guoyin, Extension of rough set under incomplete information systems. journal of computer research and development, 39(10)2002, 1238-1243.

6. Wei Huang, Cong Liu, Gang Zhang. Information system based on sub-consciousness and its rough set method. Proceedings of ICMLC2004, Shanghai, China, August 26-29, 2004. To be published by IEEE. 